\title{
Oil accident response simulation: allocation of potential places of refuge
}

\author{
R. Leiger ${ }^{1,2}$, R. Aps ${ }^{1}$, M. Fetissov ${ }^{1,2}$, K. Herkül ${ }^{1}$, M. Kopti ${ }^{1,2}$, \\ J. Kotta ${ }^{1}$, Ü. Mander ${ }^{3} \&$ Ü. Suursaar ${ }^{1}$ \\ ${ }^{I}$ Estonian Marine Institute, University of Tartu, Estonia \\ ${ }^{2}$ Estonian Maritime Academy, Estonia \\ ${ }^{3}$ Institute of Geography, University of Tartu, Estonia
}

\begin{abstract}
This paper explores the problem of allocation of potential places of refuge for a ship in distress along the Estonian coast of the Gulf of Finland balancing the advantage for the affected ship and for the environment resulting from bringing the ship into a place of refuge. The integrated oil accident response simulation environment (PISCES II, ArcGis spatial modeling tools and Bayesian Belief Networks) proved to be instrumental for operational decision support in the case of a hypothetical oil accident. The knowledge of the ecological sensitivity of the Estonian coastal sea in the Gulf of Finland is used to estimate the probability of expected ecological damage associated with different towing directions of the vessel in distress. It is shown that the choice of the most favorable towing direction of the vessel in distress depends on the season, the position of the accident, and the ecological sensitivity level of the coastal sea area concerned.

Keywords: places of refuge, vessel in distress, oil incident, ecological risk assessment.
\end{abstract}

\section{Introduction}

The Gulf of Finland is a sensitive brackish water area with a unique nature and environment. At the same time the Gulf of Finland has some of the busiest oil shipping routes in the world. According to Kuronen et al. [1] a total of 263 million tons of cargoes were transported in the Gulf of Finland and the transportation of petroleum products formed $56 \%$ of all cargo traffic in 2007 . The authors estimate that in the case of slow economic growth the ship transport 
in the Gulf of Finland would reach 322.4 million tons in 2015 (growth 23\%), while average growth would yield some 431.6 million tons (growth 64\%), and strong growth some 507.2 million tons (growth 93\%) of cargo. Despite improved navigation measures there is a growing risk of incidental oil spills and associated oil pollution. Current oil incident emergency response efforts in the Gulf of Finland are concentrated mainly on the deployment of equipment for containing and skimming spilled oil. However, the issue of towing the ship in distress away from exposed coastlines or bringing that ship into a place of refuge has attracted much less attention so far.

In November 2003, the IMO Assembly adopted the Guidelines on places of refuge for ships in need of assistance in a manner that retains a proper and equitable balance between the rights and interests of coastal States and the need to render assistance to ships that are distress at sea [2]. The Guidelines recognize that, when a ship has suffered an incident, the best way of preventing damage or pollution from its progressive deterioration is best carried out in a place of refuge. However, bringing such a ship into a place of refuge may endanger the coastal State, both economically and from the environmental point of view, and local authorities and the population may strongly object to the operation.

According to IMO Guidelines, in the case of an accident, when permission to access a place of refuge is requested, there is no obligation for the coastal authority to grant it, but the coastal authority is going to weigh all the factors and risks in a balanced manner and give shelter whenever reasonably possible. Political decisions on the possible towing destination for a ship in distress are negotiated between coastal authorities, with aim the of selecting the best towing destination alternative through weighting of the advantages and disadvantages of the different towing destinations and of their expected net benefit towards, or net reduction of the overall environmental impact. A comprehensive review of the state of the play as regards the allocation of places of refuge in the Baltic Sea is given by Ohlson [3].

Bayesian inference and the Bayesian Belief Networks (BBNs) are increasingly used in ecological studies [4-5] because BBNs are able to employ subjective interpretations of probability, and they immediately direct the analyst to the full distributional qualities of parameter uncertainty, through the posterior distribution function [6].

Based on the probabilistic modeling the problem of ecological risk assessment related to allocation of potential places of refuge for a ship in distress along the Estonian coast of the Gulf of Finland is analyzed.

\section{Material and methods}

Ecological sensitivity maps used in this study are based on three different ecosystem elements: the EU Habitat Directive Annex 1 habitats and associated habitat forming species, birds and seals. In each raster cell the maximum value of different layers is calculated to give the final assessment of ecosystem sensitivity by coastal water bodies and the seasons (Figure 1). 


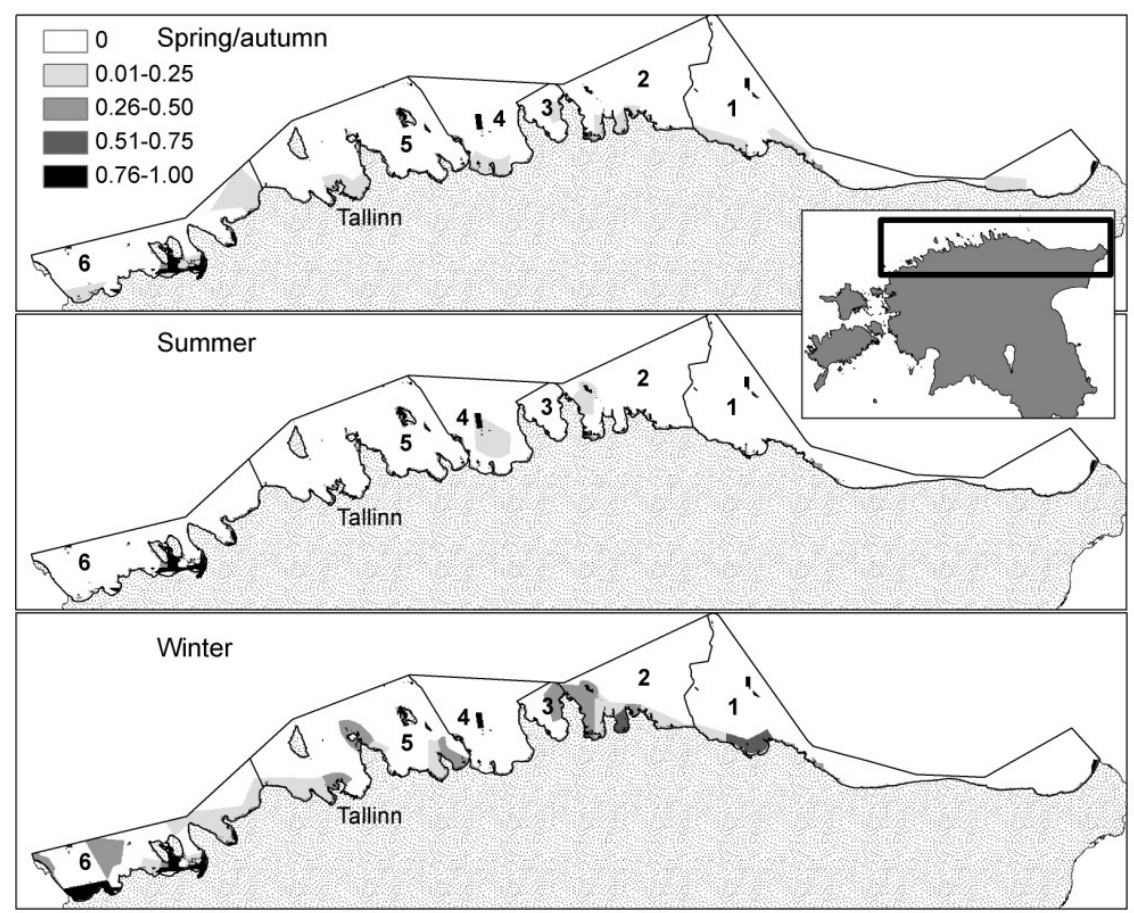

Figure 1: Ecological sensitivities by coastal water bodies of the southern Gulf of Finland $(1-6)$ and seasons (spring/autumn, summer and winter). Sensitivity scale according to sensitivity criteria applied: (0) - no sensitivity, (0-0.25) - low sensitivity, (0.26-0.50) medium sensitivity, (0.51-0.75) - high sensitivity, and (0.76-1.00) - very high sensitivity [7].

According to technical documentation [8] Seatrack Web's modeling suite calculates the spreading of oil that has come out in the Gulf of Bothnia, the Gulf of Finland, the Baltic Sea, the Sounds, the Kattegat, the Skagerack and part of the North Sea. Seatrack Web has access to forecasted current fields of the Hiromb model (HIgh Resolution Operational Model for the Baltic), which is a 3dimensional circulation model covering the whole Baltic Sea and part of the North Sea. Every 3 hour new current fields are used in Seatrack Web with the horizontal grid resolution of 3 nautical miles. Hiromb gives the currents at 24 different depth levels and those influence the drift and spreading of the substance.

The wind forecasts used in Seatrack Web originate from the weather model at the European Centre for Medium-Range Weather Forecasts (ECMWF) 5 days ahead and High Resoluted Limited Area weather Model (HIRLAM) 2 days ahead. The wind forecasts used in Seatrack Web are from 10 meters height.

PISCES II (Potential Incident Simulation Control and Evaluation System) is used to simulate development of an oil spill incident scenarios [9]. The PISCES II 
spill model simulates processes in an oil spill on the water surface: transport by currents and wind, spreading, evaporation, dispersion, emulsification, viscosity variation, burning, and interaction with booms, skimmers, and the coastline (stranding or beaching).

The following factors are taken into consideration in the mathematical model: 1) environmental parameters: coastline, field of currents, weather, wave height and water density, 2) physical properties of spilled oil: specific gravity, surface tension, viscosity, distillation curve and emulsification characteristics, 3) properties of spill sources, and 4) human response actions: booming, onwaterrecovery, application of chemical dispersants as and when necessary.

HUGIN RESEARCHER software is used to construct the BBNs for ecological risk assessment. According to [7] this BBN network contains three information variables: (1) "Season" (winter, spring/autumn and summer), (2) "Ecological Sensitivity" (no sensitivity, low sensitivity, medium sensitivity, high sensitivity and very high sensitivity to potential oil spill related pollution), and (3) "Water Body" containing the information on the number of raster cells that are related to different states of ecological sensitivity.

A utility node "Number of Raster Cells" is used to indicate the total number of raster cells (water bodies 1 to 6 ) of chosen sensitivity status for the certain season. A hypothesis variable "Risk Distribution" is representing the ecological risk distribution over the all six water bodies concerned for the given season and the chosen ecological sensitivity status.

\section{Results and discussion}

Assessment of ecological risk related to 1) accidental instantaneous oil spill in the Western Gulf of Finland, and 2) towing of continuously spilling vessel in distress to a closest allocated place of refuge in Western and the Eastern Gulf of Finland respectively is exemplified below by the three following hypothetical scenarios.

\subsection{Scenario I}

Oil tanker carrying the medium oil gets damaged in the Western Gulf of Finland and this accident resulted in the instantaneous spill of 100 tons of medium oil. Immediately after notification of an oil accident at sea, the quick decision is to be taken on the most appropriate option(s) on handling the ship in distress. This decision is based on the following information: 1) what are the expected drift, behavior and fate of the spilled oil, and 2) is the oil threatening a sensitive resource?

What would be the ecological risk in a case if the decision will not be made to tow the damaged tanker to the nearest designated port of refuge? Seatrack Web modeling suite was used to calculate the hypothetical trajectory of the spilled oil (Figure 2).

Trace of spilled oil is calculated taking into account the weather related uncertainty (Figure 3). 


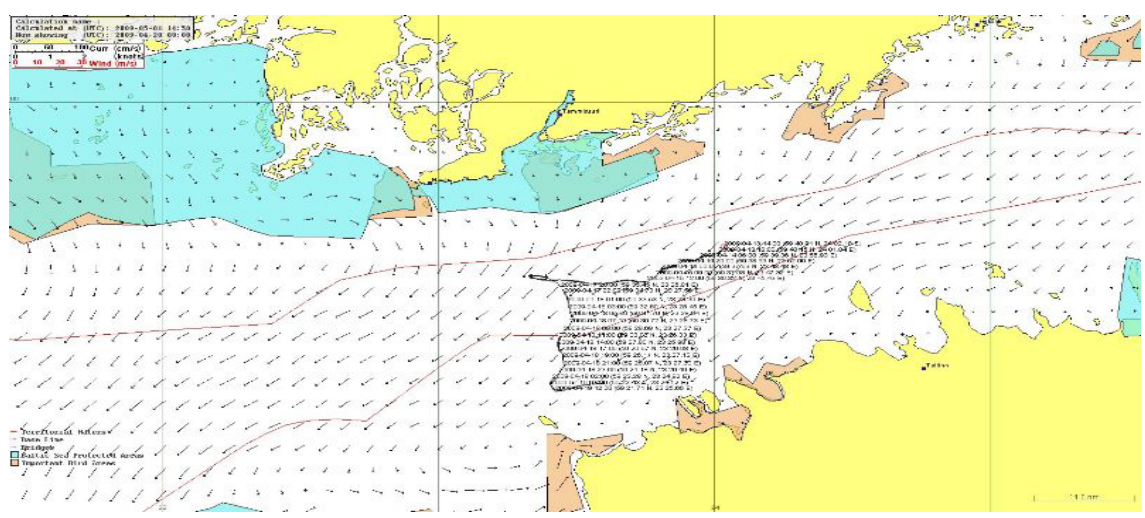

Figure 2: $\quad$ Trajectory of the accidentally spilled medium oil in the Western Gulf of Finland calculated using the actual weather conditions for the period starting on 13 April 2009 (12:00 UTC, Coordinated Universal Time) and ending on 20 April 2009 (00:00 UTC). Arrows show the direction and speed of the surface current. The locations of Important Bird Areas and the Baltic Sea Protected Areas are shown along the coasts.

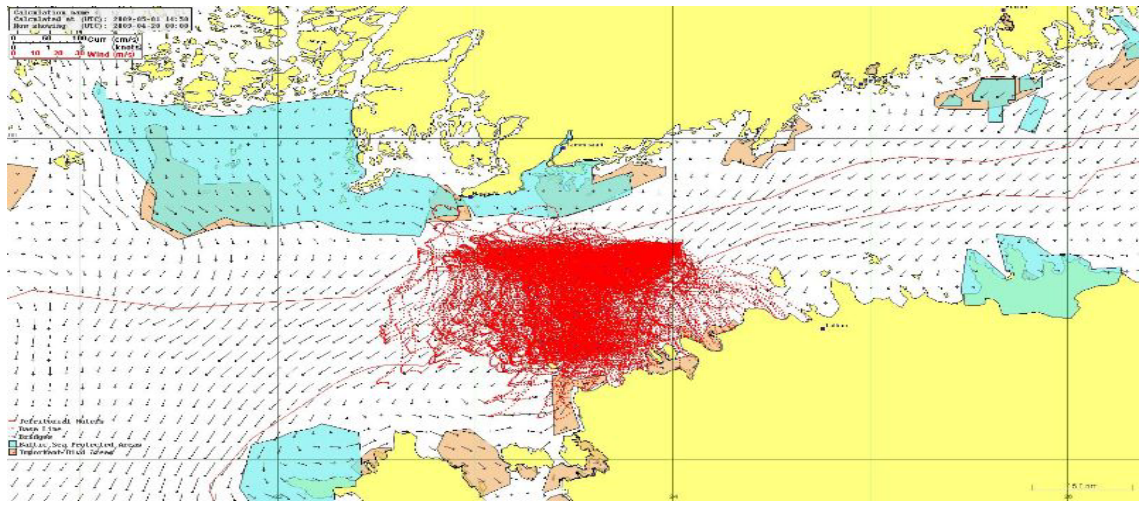

Figure 3: $\quad$ Trace (including uncertainty) of the accidentally spilled medium oil in the Western Gulf of Finland calculated using the actual weather conditions for the period starting on 13 April 2009 (12:00 UTC) and ending on 20 April 2009 (00:00 UTC). Arrows show the direction and speed of the surface current. The locations of Important Bird Areas and the Baltic Sea Protected Areas are shown along the coasts.

In Seatrack Web modeling suite the uncertainty in a drift simulation, so called uncertainty spreading is calculated in a way that each particle is given an additional random velocity whose magnitude is a function of the expected uncertainty in the wind forecast. The idea is to mimic an ensemble of simulations with slightly different forcing while only particles on the surface are affected [8]. 


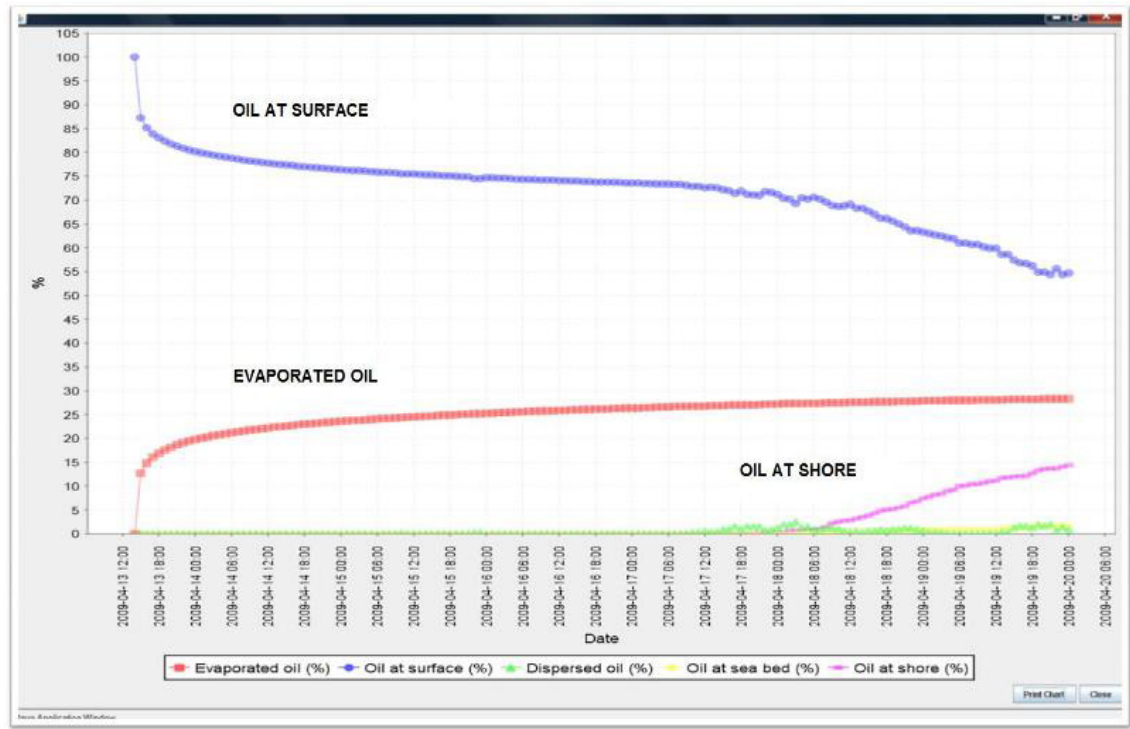

Figure 4: The fate of the 100 tons of medium oil accidentally spilled in the Western Gulf of Finland (oil at surface, evaporated oil, oil washed ashore, dispersed oil, and the oil at sea bed) simulated by Seatrack Web using the actual weather conditions for the time period: 13 April 2009 (12:00 UTC) - 20 April 2009 (00:00 UTC).

The fate of the spilled oil in the sea environment is also calculated by Seatrack Web and presented in Figure 4.

Figure 4 shows that after 180 hours from the accident time and with no human response action about $55 \%$ of the spilled oil are still at the sea surface, some $30 \%$ of the oil is evaporated, and some $15 \%$ of the oil is washed ashore by that time. Amount of dispersed oil and the oil at sea bed is small and can be neglected in that particular case. It is important to note, that in this case there is about 100 hours available for possible response actions (use of booms and skimmers depending on actual weather conditions) before the oil starts increasingly come ashore. According to HELCOM Recommendation 22/2 "Restricted use of chemical agents and other non-mechanical means in oil combating operations in the Baltic Sea area" [10], it was recommended that, due to the sensitive ecological conditions in the Baltic Sea area, response to oil should take place by the use of mechanical means as far as possible while response by using dispersants should be limited. Therefore, the option of dispersants use is not considered within this study. Usually, booms and skimmers are the first technique employed to remove oil from marine environments but this technique can usually recover relatively small proportion of the spilled oil because of quite narrow window of opportunity depending on the actual weather conditions. 


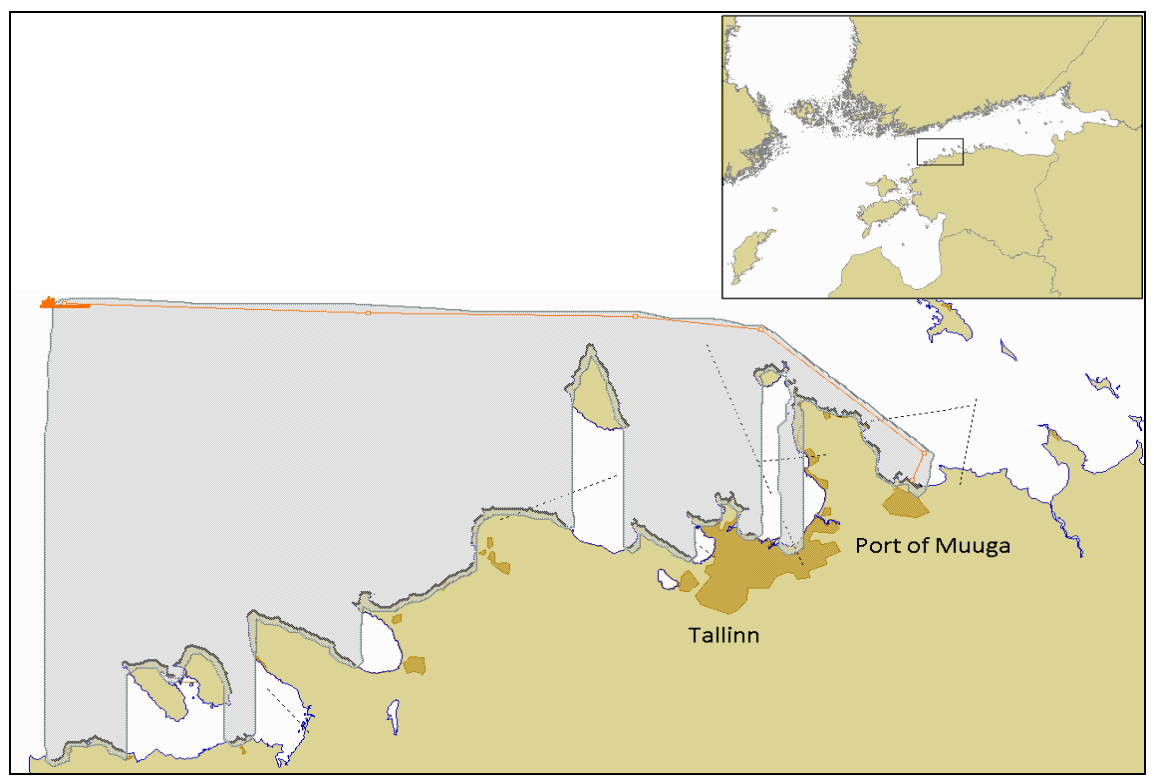

Figure 5: PISCES II simulation of the oil spilling vessel in distress taken from an accident site to the designated port of refuge - Port of Muuga. Distance $74,1 \mathrm{~km}$, time of response action 04:56 hours, spill rate -60 tons per hour.

\subsection{Scenario II}

Oil tanker carrying the medium oil gets damaged in the Western Gulf of Finland and this accident resulted in the continuous spill with a rate of 60 tons per hour of medium oil. Decision was taken to bring the vessel in distress to the closest designated port of refuge - the Port of Muuga (Figure 5).

This is one of the worst case scenarios (sea surface current is coming straight towards the Estonian coast of the Gulf of Finland and the situation is not changing during the action) that is representing roughly the severe environmental consequences of the accident despite of the human response action taken. Simulation results suggest that in similar cases everything possible should be done to prevent oil to wash ashore because there are obvious advantages if the spilled oil that threatens ecologically sensitive coastal sea area can be removed while it is still at sea.

\subsection{Scenario III}

Oil tanker carrying the medium oil gets damaged in the Eastern Gulf of Finland and this accident resulted in the continuous spill with a rate of 60 tons per hour of medium oil. Decision was taken to bring the vessel in distress to the closest designated port of refuge - the Port of Sillamäe (Figure 6). 


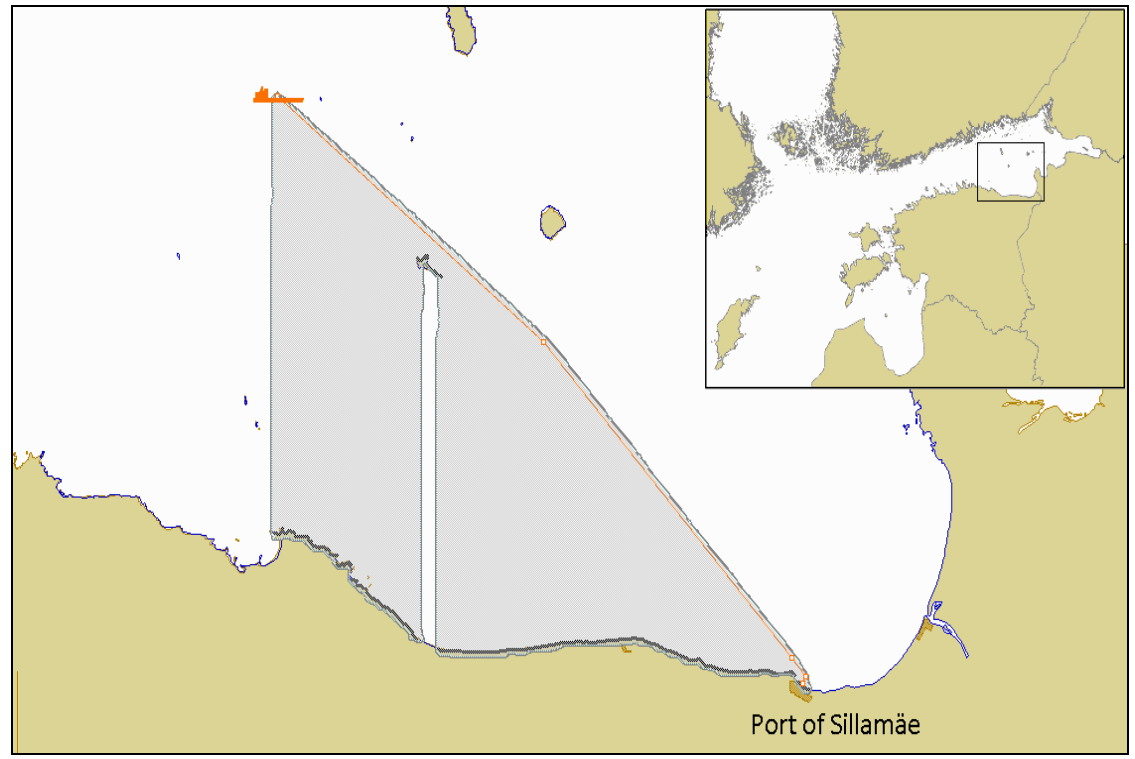

Figure 6: PISCES II simulation of the oil spilling vessel in distress taken from an accident site to the designated port of refuge - Port of Sillamäe. Distance 92,9 km, time of response action 06:12 hours, spill rate -60 tons per hour.

Conclusions that can be drawn based on the results of the Scenario III simulation are very similar to those related to Scenario II results. In these worst case scenario situations everything possible should be done to prevent the oil to wash ashore.

\section{Ecological risk assessment}

A BBN constructed with aim to assess the accidental oil spill related ecological risk is primarily used to update the ecological risk probability distribution over the states of a hypothesis variable, which is not directly observable. Ecological risk distribution then helps a decision maker in deciding upon an appropriate course of action. For example, in a case of Scenarios I and II the EU Water Directive water quality assessment water bodies 5 and 6 will be affected (compare Figures 1, 3 and 5). If the ecological risk distribution is calculated for variable "Season" in a state equal to "Winter" and the variable "Ecological Sensitivity" in a state equal to "Very High" then the risk that the habitats of very high ecological sensitivity will be damaged is $61.91 \%$ and the $12.99 \%$ respectively for the water bodies 5 and 6 (Figure 7).

At the same time, in a case of Scenario III the EU Water Directive water quality assessment water body 1 will only be affected (compare Figures 1 and 6). In this case the risk that the habitats of very high ecological sensitivity will be damaged is only $7.14 \%$ for the affected water body 1 (Figure 7 ). 


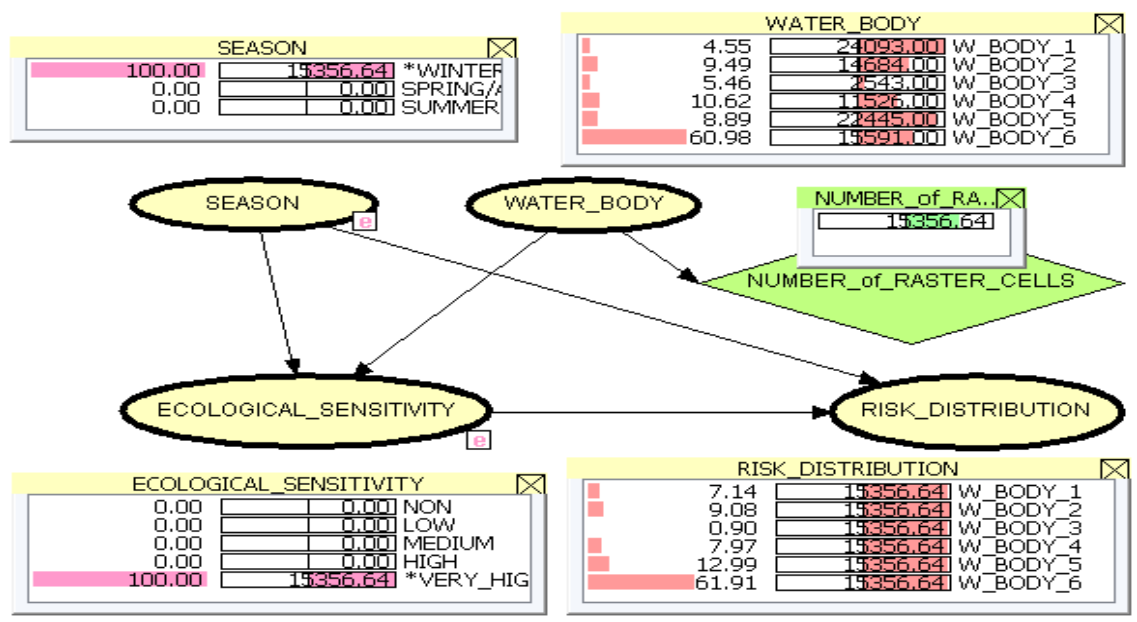

Figure 7: $\quad$ Ecological risk assessment BBN for the southern Gulf of Finland (Baltic Sea) by the EU Water Directive water quality assessment water bodies 1-6 (winter, high sensitivity) [7].

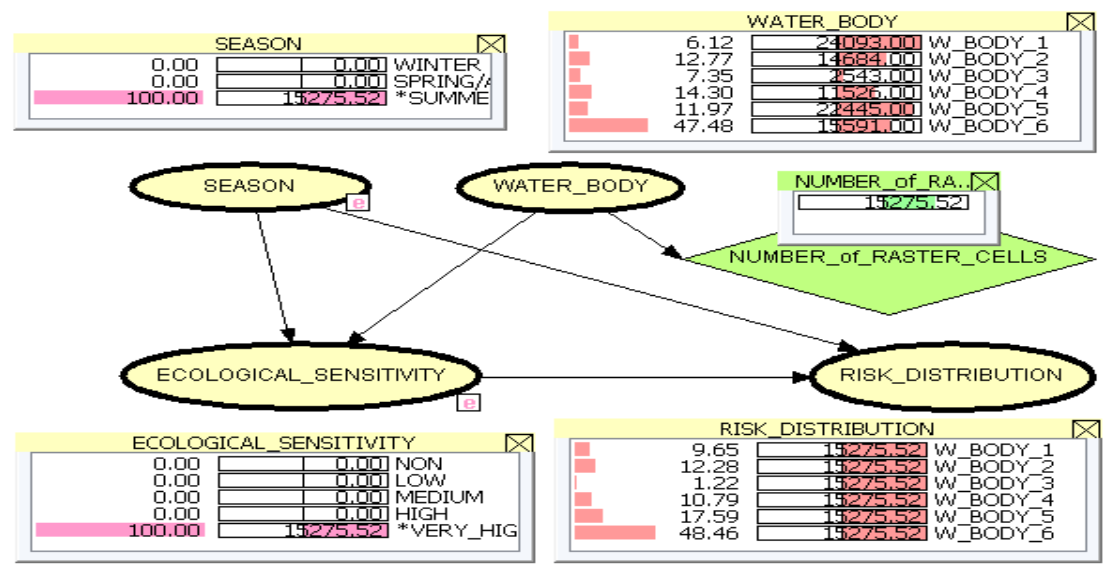

Figure 8: $\quad$ Ecological risk assessment $\mathrm{BBN}$ for the southern Gulf of Finland (Baltic Sea) by the EU Water Directive water quality assessment water bodies 1-6 (summer, high sensitivity) [7].

If the ecological risk distribution is calculated for variable "Season" in a state equal to "Summer" (summer time accident) then the risk that the habitats of very high ecological sensitivity will be damaged is in a case of scenarios I and II $48.46 \%$ and the $17.46 \%$ respectively for the water bodies 5 and 6 while in a case of scenario III the risk that the habitats of very high ecological sensitivity will be damaged is only $6.12 \%$ (Figure 8 ). 
Seasonal differences in ecological risk distribution are largely related to temporal presence of the bird species that are listed in the EU Birds directive Annex 1, and included into the sensitivity analyses [7]. According to the common eider (Somateria mollissima) was included because the abundance of this species had notably declined in recent years and the species is known to be very sensitive to oil spills. The sensitivity of bird species to oil pollution is assessed on the basis of the bird oil vulnerability index (OVI). The OVI index values above 60 refer to bird species of high sensitivity while OVI values between 30 and 60 show that the species are moderately affected by spilled oil and the index values below 30 indicates that oil has little effect on the species. The species that fitted the selection criteria and are present in the sea area concerned are as follows: Bewick's swan or tundra swan (Cygnus columbianus) (low sensitivity), whooper swan (Cygnus cygnus) (low sensitivity), Steller's eider (Polysticta stelleri) (high sensitivity), merganser (Mergus albellus) (medium sensitivity), common eider (S. mollissima) (high sensitivity).

It is important to add that the scenarios I - III are presenting the rough worst cases in a sense that the whole area of the water quality assessment water body is damaged by the hypothetical accidental oil pollution. The objective of our future work is to develop the probabilistic risk assessment framework for the Estonian coastal sea areas of any spatial configuration broken down by seasons and the ecological sensitivity levels. The web based (ArcGIS Server Application) dynamic ecological sensitivity map that has been developed by the Estonian Marine Institute, University of Tartu is believed to be used as a basis for that framework (Figure 9).

In future we aim also to expand upon further integration of the BBNs with the Seatrack Web and the PISCES II simulation suits.

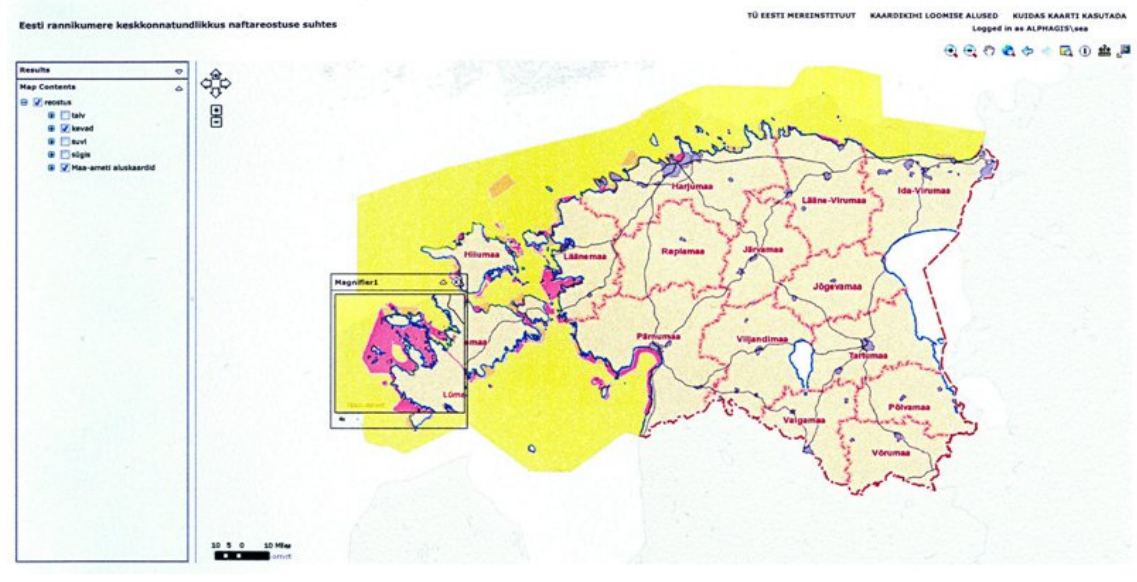

Figure 9: Estonian Baltic coastal sea ecological sensitivity web based ArcGIS map application (four seasons and five ecological sensitivity levels). 


\section{Conclusions}

1. Comparison of the assessed ecological risk in the Western Gulf of Finland related to 1) accidental instantaneous oil spill, and 2) the towing of continuously spilling vessel in distress to a closest allocated place of refuge shows that the level of ecological risk related to the instantaneous medium size oil spill with no human response action is similar to the level of ecological risk related to taking the spilling vessel in distress into the designated port of refuge.

2. Simulation results suggest that in a case of the accident similar to the simulated scenario everything possible should be done to prevent the oil of washing ashore because there are obvious advantages if the spilled oil that threatens ecologically sensitive coastal sea area can be removed while it is still at sea. Use of dispersants is not recommended due to sensitive ecological conditions in the Baltic Sea area.

3. In a case of accident booms and skimmers should be urgently employed 1) to surround a slick as much as possible and reduce its spread, 2) to protect to extent possible the biologically sensitive areas, and 3) when and as possible to divert oil to an area where it can be recovered despite of fact that this technique can usually recover relatively small proportion of the spilled oil due to quite narrow window of opportunity that is depending on the actual weather conditions and the mobilization time of the response equipment.

\section{Acknowledgements}

The study was supported by the Estonian target financing programs SF0180104s08 and SF0180013s08.

\section{References}

[1] Kuronen, J., Helminen R., Lehikoinen A., \& Tapaninen U. Maritime transportation in the Gulf of Finland in 2007 and in 2015. University of Turku. 114 p. 2008.

[2] IMO Resolution A.949 (23) - Guidelines on Places of Refuge for Ships in need of Assistance. Assembly 23rd session. 14 p. 2003.

[3] Ohlson, J.H. The state of play as regards the allocation of places of refuge in the Baltic Sea. Dissertation, M.Sc. in Maritime Administration. World Maritime University, Malmö, Sweden. 86 p. 2006.

[4] Borsuk M.E., Stow C.A., Reckhow K.H. A Bayesian network of eutrophication models for synthesis, prediction, and uncertainty analysis. Ecological Modeling 173:219-239. 2004.

[5] Ellison A.M. An introduction to Bayesian inference for ecological research and environmental decision making. Ecological Applications 6, pp. 410361046, 1996. 
[6] Ellison A.M. Bayesian inference in ecology. Ecological Letters 7, pp. 509520. 2004.

[7] Aps, R., Fetissov, M., Herkül, K., Kotta, J., Leiger, R., Mander, Ü., Suursaar, Ü. Bayesian inference for predicting potential oil spill related ecological risk. SAFE 2009. WIT Transactions. In press. 2009.

[8] Technical documentation Seatrack Web. Physical processes, numerics, algorithms and references. Version 2.4.0. 27 p. 2008.

[9] Delgado, L., Kumzerova, E., Martynov, M. Simulation of oil spill behavior and response operations in PISCES. Environmental Problems in Coastal Regions VI including Oil Spill Studies. Ed. C.A. Brebbia, Wessex Institute of Technology, pp. 279-292. 2006.

[10] HELCOM Recommendation 22/2. Restricted use of chemical agents and other non-mechanical means in oil combating operations in the Baltic Sea area. 1 p. 2002. 